\title{
Avaliação do valor nutricional do resíduo de abacaxi pela técnica in situ em ruminantes
}

\author{
Jessyca Karen Pinheiro' $^{1 *}$, Lara Toledo Henriques ${ }^{1}$, Adeilson de Melo Silva ${ }^{1}$
}

\begin{abstract}
RESUMO: Objetivou-se com este estudo avaliar o valor nutricional do resíduo de abacaxi pela técnica in situ em ruminantes. A quantificação da degradabilidade da matéria seca (MS) e fibra em detergente neutro (FDN) ocorreu por incubação in situ com amostras do resíduo de abacaxi, que foram acondicionados em sacos de tecido não-tecido (TNT $100 \mathrm{~g} / \mathrm{m}^{2}$ ) com dimensões de $12 \times 20 \mathrm{~cm}$, respeitando a proporção de $20 \mathrm{mg}$ de $\mathrm{MS} / \mathrm{cm}^{2}$. Os tempos de permanência das amostras no rúmen para estimativa do desaparecimento da MS e FDN foram: 0, 12, 24, 48, 72, 96,120 e 144 horas, além dos tempos 240 e 264 horas, para determinação da fibra em detergente neutro indigestível (FDNi) e fibra em detergente ácido indigestível (FDAi), respectivamente. O resíduo de abacaxi apresentou teor de FDN de 57.9\%, e teor proteico de $6.06 \%$. A degradação potencial da MS e FDN mostrou-se elevado (87.1\%), apesar do alto teor de lignina (20.2\%) no resíduo. O resíduo de abacaxi possui composição química e degradabilidade ruminal dos nutrientes que permitem o uso na alimentação de ruminantes como fonte de volumoso, sendo recomendável o emprego de suplementação proteica para otimizar a degradação da fibra.
\end{abstract}

Palavras-chave: composição química, degradabilidade, fração proteica não degradável

\section{Evaluation of the nutritional value of the pineapple residue by in situ technique in ruminants}

\begin{abstract}
The objective of this study was to evaluate the nutritional value of the pineapple residue by in situ technique in ruminants. The dry matter (DM) and neutral detergent fiber (NDF) quantification was quantified by in situ incubation with samples of the pineapple residue, which were packed in non-woven bags (TNT - $100 \mathrm{~g} / \mathrm{m}^{2}$ ) with dimensions of $12 \times 20 \mathrm{~cm}$, respecting the ratio of $20 \mathrm{mg}$ of $\mathrm{MS} / \mathrm{cm}^{2}$. The rumen samples were kept at $0,12,24,48,72$, 96, 120 and 144 hours, in addition to the 240 and 264 hours, to determine the neutral detergent fiber indigestible fiber (iNDF) and indigestible acid detergent fiber (iADF), respectively. The pineapple residue presented NDF content of $57.9 \%$, and protein content of $6.06 \%$. The potential degradation of DM and NDF was high (87.1\%), despite the high lignin content $(20.2 \%)$ in the residue. The pineapple residue has chemical composition and ruminal degradability of the nutrients that allow the use in ruminant feed as a source of bulky, and it is recommended the use of protein supplementation to optimize fiber degradation.
\end{abstract}

Keywords: chemical composition, degradability, non-degradable protein fraction

\section{INTRODUÇÃO}

$\mathrm{O}$ processamento de frutas para a produção de sucos gera, anualmente, grandes quantidades de resíduos agroindustriais, que possuem grande potencial de uso na alimentação de ruminantes, podendo contribuir para a otimização do desempenho animal e, de modo simultâneo, com a redução dos resíduos potencialmente poluentes do meio ambiente (NASCIMENTO FILHO, FRANCO, 2015).

Dentre os diversos resíduos do processamento de frutas, o resíduo pós-colheita do abacaxi (Ananas comosus) possui grande potencial de uso na dieta como fonte de volumoso, tornando-se uma importante fonte de alimento para ruminantes em períodos de escassez de forragem (FERREIRA et al.,
2009). Assim, os sistemas de produção de ruminantes podem contar com os resíduos da lavoura de frutas como uma fonte de alimento alternativo, estratégico no manejo alimentar tanto para manter o desempenho animal, como para reduzir os custos de produção, principalmente, nos períodos de baixa disponibilidade de volumoso.

O estado da Paraíba é um dos maiores produtores de abacaxi do Brasil, que por possuir agroindústrias de processamento dos frutos, acabam gerando um grande volume de resíduos que podem ser utilizados na alimentação dos rebanhos da região (NUNES et al., 2017). Contudo, o resíduo pós-colheita do abacaxi, geralmente, é considerado uma fonte de alimento de baixa qualidade, em razão da proporção

Recebido em 17/05/2019; Aceito para publicação em 14/11/2019

${ }^{1}$ Universidade Federal da Paraiba

*E-mail: jessyca.pinheiro@yahoo.com.br 
de folhas e caule. Devido a isso, apresenta baixos teores de proteína e elevado percentual de fibra (ROGÉRIO et al., 2007), que podem impor restrições nutricionais ao metabolismo microbiano.

Além disso, os resíduos de abacaxi são ricos em compostos lignocelulósicos (SILVA et al., 2018), que se associam à matriz orgânica da parede celular vegetal, impondo barreiras físicas a degradação microbiana. Nesse sentido, em condições tropicais, a disponibilidade ruminal dos compostos nitrogenados dos alimentos deve ser considerada, em razão da sua elevada associação com a fração lignocelulose, a qual pode comprometer a acessibilidade a estes compostos pelos microrganismos ruminais (CLIPES et al., 2006).

Logo, a avaliação da degradação e a estimativa de compostos indigestíveis do restolho de abacaxi através de estudos in situ, tornam-se relevantes para o conhecimento da disponibilidade ruminal dos nutrientes. Essas informações permitem a apreciação do emprego deste resíduo, em associação com outros alimentos, nas formulações de dietas para ruminantes.

Portanto, objetivou-se com este estudo avaliar o valor nutricional do resíduo de abacaxi pela técnica in situ em ruminantes.

\section{MATERIAIS E MÉTODOS}

O restolho de abacaxi foi fornecido pela Empresa de Assistência Técnica e Extensão Rural localizada em São Miguel do Taipú $\left(07^{\circ} 15^{\prime} \mathrm{S} ; 35^{\circ} 12^{\prime} \mathrm{O}\right)$, no estado da Paraíba, Brasil. Foram fornecidos aproximadamente $100 \mathrm{~kg}$ do resíduo verde da planta do abacaxi pós-colheita, sendo desprezada apenas a fração de raiz.

O resíduo verde da planta do abacaxi pós-colheita foram secos em estufa com ventilação forçada (60 ${ }^{\circ} \mathrm{C}$ por 72 horas), e processados em moinho de facas com peneira de porosidade de 1 e $2 \mathrm{~mm}$. Esse material foi quantificado quanto aos teores de matéria seca (MS; INCT-CA G-003/1); matéria mineral (MM; INCT-CA M-001/1); proteína bruta (PB; INCT-CA N-001/1); extrato etéreo (EE; INCTCA G-004/1); fibra em detergente neutro (FDN; INCT-CA F-001/1); fibra em detergente ácido (FDA; INCT-CA F-003/1) e lignina (LIG; INCT-CA F-005/1) de acordo com Detmann et al., (2012).

A quantificação da degradabilidade da matéria seca (DMS), fibra em detergente neutro (DFDN) e a avaliação dos teores de componentes indigestíveis ocorreram por incubação in situ com amostras do resíduo do abacaxi. Essas amostras foram acondicionadas em sacos de tecido não-tecido (TNT - $100 \mathrm{~g} / \mathrm{m}^{2}$ ) com dimensões de $12 \times 20 \mathrm{~cm}$, respeitando-se a proporção de $20 \mathrm{mg} \mathrm{de} \mathrm{MS} / \mathrm{cm}^{2}$, as quais foram incubadas no rúmen de um bovino mestiço, castrado, fistulado no rúmen, com peso corporal médio de $300 \mathrm{~kg}$. Para tal, o bovino foi mantido confinado em baia individual, provida de cocho e bebedouro, recebendo capim elefante picado, água e mistura mineral a vontade.

Os tempos de permanência das amostras no rúmen para estimativa do desaparecimento da MS e FDN foram: 12, 24, 48, 72, 96, 120 e 144 horas, além dos tempos 240 e 264 horas, para determinação da fibra em detergente neutro indigestível (FDNi) e fibra em detergente ácido indigestível (FDAi), respectivamente (CASALI et al., 2008). Enquanto, no tempo 0 , os sacos foram apenas imersos em água para simular o desaparecimento da fração solúvel. Após a retirada do rúmen, os sacos foram imersos em água fria para paralisação da atividade microbiana, lavados e transferidos para estufa de ventilação forçada $\left(60^{\circ} \mathrm{C}\right)$, onde foram mantidos por 72 horas. Sequencialmente, foram secos em estufa (105 ${ }^{\circ} \mathrm{C}$ por 2 horas), para obtenção da MS indigestível (MSi) (DETMANN et al., 2012).

As amostras pós-rúmen referente aos tempos de permanência até 240 horas, e o tempo 264 horas, foram tratados, respectivamente, com detergente neutro e detergente ácido em equipamento analisador de fibra Ankon ${ }^{\circledR}$ para obtenção da fração FDNi e da fração FDAi, segundo métodos descritos por Mertens (2002).

Os dados obtidos sobre o desaparecimento da MS e FDN nos diferentes tempos de incubação foram ajustados por meio do programa GOSA-fit ao modelo descrito por Ørskov, McDonald (1979), expresso por: $\mathrm{DP}=\mathrm{a}+\mathrm{b} *(1-\exp (-\mathrm{ct}))$, em que: $\mathrm{DP}=$ degradabilidade potencial $(\%) ; \mathrm{a}=$ fração solúvel $(\%) ; \mathrm{b}=$ fração potencialmente degradável $(\%) ; \mathrm{c}=$ taxa de degradação da fração potencialmente degradável $\mathrm{b}(\% / \mathrm{hora}) ; \mathrm{t}=$ tempo de incubação no rúmen (horas). As constantes resultantes foram usadas para estimar a degradabilidade efetiva seguindo a equação: $\mathrm{DE}=\mathrm{a}$ $+[(\mathrm{b} \times \mathrm{c}) /(\mathrm{c}+\mathrm{k} 1)]$, em que: $\mathrm{DE}=$ degradabilidade efetiva $(\%)$; e $\mathrm{k} 1(\% /$ hora $)=$ taxa de passagem de sólidos pelo rúmen, definida como sendo de $2 \%$ /hora, que representa uma condição de baixo consumo alimentar (AFRC, 1993).

Os teores dos compostos nitrogenados associados a parede celular: proteína indegradável insolúvel em detergente neutro (PIIDN), proteína indegradável insolúvel em detergente ácido (PIIDA) e proteína indegradável associada a lignina (PILIG) foram estimados seguindo os métodos descritos por Robertson, Van Soest (1981), Van Soest et al., (1991) e Licitra et al., (1996). Todas as avaliações de compostos nitrogenados foram conduzidas por intermédio do método de Kjeldahl (PB; INCT-CA $\mathrm{N}-001 / 1)$, utilizando-se o fator 6,25 para expressão dos teores como equivalentes proteicos. 


\section{RESULTADOS E DISCUSSÃO}

Os teores de MS, MM, PB, FDN e FDA observados neste estudo (Tabela 1), mostraram-se próximos dos valores obtidos por alguns autores (PINTO et al., 2005; CORREIA et al., 2006; BRAGA et al., 2016) avaliando o uso do resíduo de abacaxi na alimentação de ruminantes. No entanto, vale ressaltar a considerável fração proteica e fibrosa do resíduo de abacaxi obtidos no estudo, que devido a isso, tem sido apontado como uma fonte de volumoso com composição de proteina similar, inclusive, a silagem de milho (PAULA, JUNIOR, 2019).

Tabela 1. Teores de matéria seca (MS), matéria mineral (MM), proteína bruta $(\mathrm{PB})$, fibra em detergente neutro (FDN), fibra em detergente ácido (FDA) e lignina (LIG) do resíduo do abacaxi.

\begin{tabular}{lc}
\hline Nutrientes & Resíduo do abacaxi \\
\hline MS (\%) & 92.3 \\
MM (\%) & 2.37 \\
PB (\%) & 6.06 \\
FDN (\%) & 57.9 \\
FDA (\%) & 52.2 \\
LIG (\%) & 20.2 \\
\hline
\end{tabular}

Contudo, o uso de fontes de volumosos ricos em fibra e com baixa fração proteica como único alimento podem comprometer a degradação ruminal, em razão do desbalanço de nutrientes no rúmen para o crescimento microbiano. Assim, o uso de resíduos com baixo teor proteico como fonte de volumosos deve ser acompanhado de suplementação proteica adequada, com intuito de otimizar o uso da fibra (SILVA, 2014).

$\mathrm{O}$ teor de lignina obtido mostrou-se elevado, o que era esperado, em razão da elevada proporção de parede celular presente nos constituintes do resíduo de abacaxi. A lignina é um composto fenólico presente na parede celular das plantas, considerada um componente indigestível da fração fibrosa dos vegetais. Logo, a presença de lignina tende aumentar a fração indigestível, reduzindo a fração potencialmente digestível dos alimentos (AZÊVEDO et al., 2011).

A estimativa da fração indigestível dos compostos associados à parede celular permitiu verificar se o elevado teor de lignina interferiu na proporção de nutrientes potencialmente degradáveis do resíduo. Assim, o teor de MSi (18.4\%; Tabela 2) obtido após a permanência no rúmen por 240 horas, indica que $81.6 \%$ da MS do resíduo de abacaxi foi disponibilizado para crescimento microbiano. Enquanto, as frações FDNi e FDAi $(17.1 \%$, 9.8\%; Tabela 2) apontam para um potencial de degradação da FDN e FDA de $70.6 \%$ e $81.2 \%$, respectivamente. Essas respostas sugerem que apesar da elevada proporção da fração fibrosa no resíduo de abacaxi, a passagem pelo ambiente ruminal foi suficiente para que os nutrientes potencialmente digestíveis fossem degradados pelos microrganismos ruminais.

A fração LIGi após a permanência no ambiente ruminal apresentou $4.15 \%$ de fração indigestível, demonstrando que, embora a fração fenólica do resíduo seja elevada, esta apresentou $79.4 \%$ de potencial de degradação ruminal. Essa resposta está associada ao fato de existir dois tipos de lignina: core e não core. A lignina core consiste na fração insolúvel obtida após tratamento com ácido sulfúrico a $72 \%$. Enquanto, a lignina não core consiste na fração fenólica associada a polissacarídeos, que por meio da digestão ácida e/ou degradação microbiana da parede celular pode liberar monômeros de ácidos fenólicos (OLIVEIRA et al., 2005). Logo, o fato da LIG do resíduo de abacaxi ter apresentado fração digestível deve-se a liberação da lignina não core no processo de digestão.

Apesar da lignina não ser classificada como um carboidrato, sua associação com este e outros nutrientes, como a proteína, dificultam a degradação microbiana dos compostos digestíveis (SILVA, QUEIROZ, 2002).

Os componentes nitrogenados que encontram-se associados a fração insolúvel e indegradável da FDN, FDA e lignina (PIIDN; PIIDA e PILIG, respectivamente) apresentaram porção pouco significativa de proteína $(0.09 \% ; 0.12 \%$ e $0.08 \%$; Tabela 3), indicando que a fração contaminante reduziu, em média, menos de $1 \%$ do teor da fibra do resíduo de abacaxi. Assim, o elevado teor de lignina observado no presente estudo, não foi capaz de afetar a fração proteica associada a fibra do resíduo.

Tabela 2. Teores da matéria seca indigestível (MSi), fibra em detergente neutro indigestível (FDNi), fibra em detergente ácido indigestível (FDAi), lignina indigestível (LIGi), proteína indegradável insolúvel em detergente neutro (PIIDN), proteína indegradável insolúvel em detergente ácido (PIIDA) e proteína indegradável associada à lignina (PILIG) com base na matéria seca.

\begin{tabular}{lc}
\hline Parâmetro & Resíduo de abacaxi \\
\hline MSi (\%) & 18.4 \\
FDNi (\%) & 17.1 \\
FDAi (\%) & 9.80 \\
LIGi (\%) & 4.15 \\
\hline PIDN (\%) & 0.09 \\
PIDA (\%) & 0.12 \\
PLIG (\%) & 0.08 \\
\hline
\end{tabular}

Os parâmetros de degradação da MS e FDN da fração " $a$ " apresentaram valores de 29.0 e $15.8 \%$, respectivamente. Esse fração representa a porção solúvel dos carboidratos e proteínas que possuem elevada disponibilidade ruminal. Considerando o resíduo como a fonte de volumoso, constituído principalmente de polissacarídeos de parede celular, o sincronismo de 10 a $20 \%$ de energia para rápido crescimento microbiano, sugere ter sido adequado 
para o desenvolvimento de microrganismos celulolíticos e hemicelulolíticos responsáveis pela degradação da fibra.

Enquanto isso, a fração potencialmente degradável " $b$ ", apresentou valores de 58.1 e $71.3 \%$, respectivamente, para a MS e FDN (Tabela 3). Valores de fração " $a$ " e " $b$ " da degradação da MS e FDN observados neste estudo estão próximos aos constatados por Braga et al. (2016) avaliando a degradabilidade ruminal de resíduos da agroindústria de frutas.

Apesar da elevada proporção de lignina no resíduo de abacaxi, a degradação potencial da MS mostrou-se elevada, indicando que este alimento tem potencial de uso na alimentação de ruminantes, uma vez $87.1 \%$ da MS tornou-se disponível para os microrganismos no rúmen. Assim, é possível verificar que, a degradabilidade da FDN (87.1\%; Tabela 3) acompanhou o comportamento de degradação da MS do resíduo, em razão da fração fibrosa está contida na MS do alimento.

A taxa de degradação " $c$ " da MS foi superior ao da FDN (1.60 vs. 0.98\%/h; Tabela 3), indicando que o menor desaparecimento contribuiu para maior taxa de degradação ruminal. Isso ocorre, pelo fato da taxa de degradação da fração potencialmente degradável de um nutriente variar em função do período de retenção do alimento no rúmen, uma vez que quanto menor for a sua digestão, maior será o tempo de permanência deste alimento no ambiente ruminal (MERTENS, 2005). Tal fato pôde ser constatado nos dados de degradabilidade efetiva, de modo que, a taxa de degradação a $2 \% / \mathrm{h}$ proporcionou redução da degradação tanto da MS como FDN, quando comparado com a degradabilidade potencial (87.1 vs. $86.4 \%$; e 87.1 vs. $85.7 \%$; Tabela 3).

Tabela 3. Fração solúvel (a), fração potencialmente degradável (b), taxa de degradação da fração b (c), degradabilidade potencial e efetiva a $2 \% / \mathrm{h}$ da matéria seca (MS) e da fibra em detergente neutro (FDN) do resíduo de abacaxi.

\begin{tabular}{lccccc}
\hline & \multicolumn{5}{c}{ Resíduo de abacaxi } \\
\cline { 2 - 6 } & \multicolumn{5}{c}{ Parâmetros } \\
\cline { 2 - 6 } & $\mathrm{a}(\%)$ & $\mathrm{b}(\%)$ & $\mathrm{c}(\% / \mathrm{h})$ & $\begin{array}{c}\mathrm{DP}^{1} \\
(\%)\end{array}$ & $\begin{array}{c}\mathrm{DE}^{2} \\
2 \% / \mathrm{h}\end{array}$ \\
\cline { 2 - 6 } MS & 29.0 & 58.1 & 1.60 & 87.1 & 86.4 \\
FDN & 15.8 & 71.3 & 0.98 & 87.1 & 85.7 \\
\hline
\end{tabular}

${ }^{1}$ DP: degradabilidade potencial; ${ }^{2} \mathrm{DE}$ : degradabilidade efetiva.

A degradabilidade da MS e da FDN do resíduo de abacaxi até as 144 horas de permanência no rúmen apresentaram comportamento crescente (Figura 1 e 2). Sendo que, a degradabilidade da MS e da fração fibrosa até as 48 horas de permanência do alimento no ambiente ruminal foram de $48.5 \mathrm{e}$ $37.3 \%$, respectivamente.

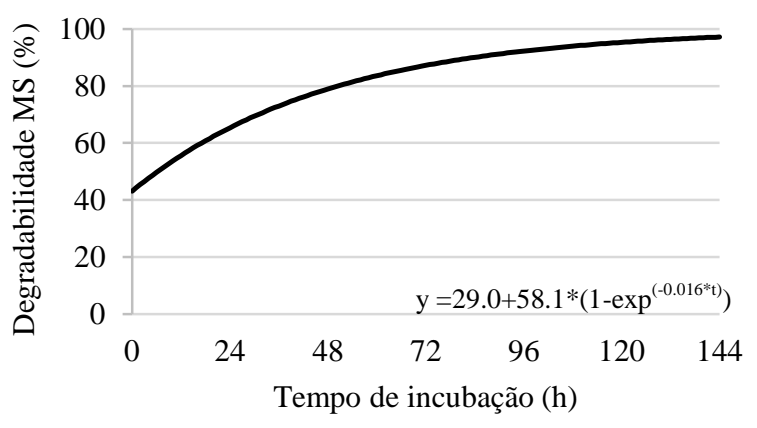

Figura 1. Degradabilidade da matéria seca (MS) do resíduo de abacaxi

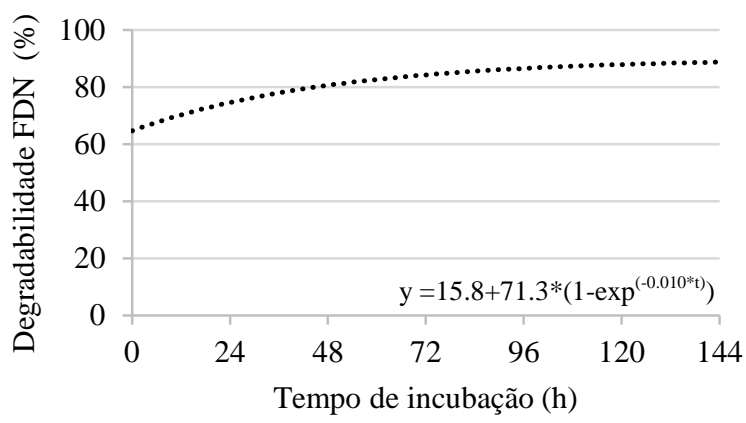

Figura 2. Degradabilidade da fibra em detergente neutro (FDN) do resíduo de abacaxi

Portanto, verificar a composição química, os componentes indigestíveis e a dinâmica de degradação dos nutrientes do resíduo de abacaxi, torna-se uma informação imprescindível para a incorporação dessa fonte de volumoso nas formulações de dietas para ruminantes.

\section{CONCLUSÃO}

O resíduo de abacaxi possui composição química e degradabilidade ruminal dos nutrientes que permitem o uso na alimentação de ruminantes como fonte de volumoso, sendo recomendável o emprego de suplementação proteica para otimizar a degradação da fibra.

\section{REFERÊNCIAS BIBLIOGRÁFICAS}

AFRC. Energy and Protein Requirements of Ruminants. Advisory Manual, Agricultural and Food Research Council Technical Committee on Responses to Nutrients. CAB International: Wallingford, 1993.

AZEVÊDO, J. A. G; VALADARES FILHO, S. C.; PINA, D. S.; DETMANN, E.; DINIZ, R. F; PEREIRA, L. G. R.; SOUZA, N. K. P.; COSTA E SILVA, L. F. Consumo, digestibilidade total, produção de proteina microbiana e balanço de nitrogênio em dietas com subprodutos de frutas para ruminantes. Revista Brasileira de Zootecnia, v. 40, p. 1052-1060, 2011.

BRAGA, A. P. AMÂNCIO, A. V. A. F.; GONÇALVES, J. S.; ASSIS, L. C. S. L. C.; SOUZA, C. M. S; MAIA, I. S. A. S.; GUERRA, D. G. F. Ruminal degradability of 
agro-industrial fruit residues. Semina: Ciências Agrárias, v. 37, n. 1, 2016.

CASALI, A. O.; DETMANN, E.; VALADARES FILHO, S. C.; PEREIRA, J. C.; HENRIQUES, L. T.; FREITAS, S. G.; PAULINO, M. F. Influência do tempo de incubação e do tamanho de partículas sobre os teores de compostos indigestíveis em alimentos e fezes bovinas obtidos por procedimentos in situ. Revista Brasileira de Zootecnia, v. 37, n. 2, p. 335-342, 2008.

CLIPES, R. C.; DETMANN, E.; SILVA, J. F. C.; VIEIRA, R. A. M.; NUNES, L. B. M.; LISTA, F. N.; PONCIANO, N. J. Evaluation of acid detergent insoluble protein as an estimator of rumen non-degradable protein in tropical grass forages. Arquivo Brasileiro de Medicina Veterinária e Zootecnia, v. 58, n. 4, p. 694697, 2006.

CORREIA, M. X. C.; COSTA, R. G.; SILVA, J. H. V.; CARVALHO, F. F. R.; MEDEIROS, A. N. Utilização de resíduo agroindustrial de abacaxi desidratado em dietas para caprinos em crescimento: digestibilidade e desempenho. Revista Brasileira de Zootecnia, v. 35, n. 4, p. 1822-1828, 2006.

DETMANN, E. Métodos para análises de alimentos. 1.ed. Visconde do Rio Branco: Suprema, 2012. 214p.

FERREIRA, A. C. H.; NEIVA, J. N. M.; RODRIGUEZ, N. M.; CAMPOS, W. E.; BORGES, I. Nutritional evaluation of pineapple industry by-product as additive on elephant grass silage. Revista Brasileira de Zootecnia, v. 38 , n. 2, p. 223-229, 2009.

NUNES, J. S.; LINS, A. D. F.; GOMES, J. P.; SILVA, W. P.; SILVA, F. B. Influência da temperatura de secagem nas propriedades físico-química de resíduos abacaxi. Agropecuária Técnica, v. 38, n. 1, p. 41-46, 2017.

LICITRA, G.; HERNANDEZ, T. M.; VAN SOEST, P. J. Standardization of procedures for nitrogen fractionation of ruminant feeds. Animal Feed Science and Technology, v. 57, p. 347-358, 1996.

MERTENS, D. R. Gravimetric determination of amylasetreated neutral detergent fiber in feeds with refluxing in beaker or crucibles: collaborative study. Journal of AOAC International, v. 85, p. 1217-1240, 2002.

MERTENS, D. R. Rate and extention of digestion. In: DIJKSTRA, J.; FORBES, J. M; FRANCE, J. Quantitative aspects of ruminants digestion and metabolism. 2.ed., Madison: USDA, p. 13-48, 2005.

NASCIMENTO FILHO, W. B.; FRANCO, C. R. Avaliação do potencial dos resíduos produzidos através do processamento agroindustrial no Brasil. Revista Virtual de Química, v. 7, n. 6, p. 1968-1987, 2015.

OLIVEIRA, R. L.; ITAVO, L. C. V; ITAVO, C. C. B. F. Fatores intrinsecos da parede celular que influenciam no consumo e digestibilidade em ruminantes. In: Nutrição de ruminantes: aspectos relacionados a digestibilidade e ao aproveitamento de nutrientes. Campo Grande: UCDB, 2005. 184p.

PAULA, K. S. A.; FARIA JUNIOR, O. L. Utilização dos restos culturais e resíduos da industrialização de abacaxi na alimentação de ruminantes: Revisão. PUBVET, v. 13, n. 2, p. 1-7, 2019.

PINTO, C. W. C.; SOUSA, W. H.; PIMENTA FILHO, E. C.; CUNHA, M. G. G.; GONZAGA NETO, S. Desempenho de cordeiros Santa Inês terminados com diferentes fontes de volumosos em confinamento. Agropecuária Técnica, v. 26, n. 2, p. 123-128, 2005.

ROBERTSON, J. B.; VAN SOEST, P. J. The detergent system of analysis and its application to humam foods. In: JAMES, W. P. T.; THEANDER, O. (Eds.). The analysis of dietary fiber in food. New York: Marcel Dekker, 1981. p. 123-158.

ROGERIO, M. C. P.; BORGES, I.; NEIVA, J. N. M.; RODRIGUEZ, N. M.; PIMENTEL, J. C. M.; MARTINS, G. A.; RIBEIRO, T. P.; COSTA, J. B.; SANTOS, S. F.; CARVALHO, F. C. Nutritive value of pineapple byproduct (Ananas comosus L.) in diets for sheep. 1. Intake, apparent digestibility, energetic and nitrogenous balance. Arquivo Brasileiro de Medicina Veterinária e Zootecnia, v. 59, n. 3, p. 773-781, 2007.

SILVA, D. J.; QUEIROZ, A. C. Análises de alimentos (métodos químicos e biológicos). 3.ed. Viçosa, MG: Editora UFV, 2002. 235p.

SILVA, M. L. S. Avaliação nutricional de silagem de restos culturais de abacaxi pérola. 36 p. Dissertação (mestrado) - Universidade Estadual Paulista, Faculdade de Ciências Agrárias e Veterinárias, Jaboticabal, 2014.

SILVA, J. S.; MALTA, V. R. S.; SANTOS-ROCHA, M. S. R.; ALMEIDA, R. M. R. G.; GOMES, M. A.; VICENTE, C. D.; BARBOSA, K. L. Enzymatic hydrolysis, fermentation and biofuels production from Ananas comosus crown. Química Nova, v. 41, n. 10, p. 1127-1131, 2018.

VAN SOEST, P. J.; ROBERTSON, J. B. Analysis of forages and fibrous foods. Ithaca: Cornell University, 1985. 202p. 